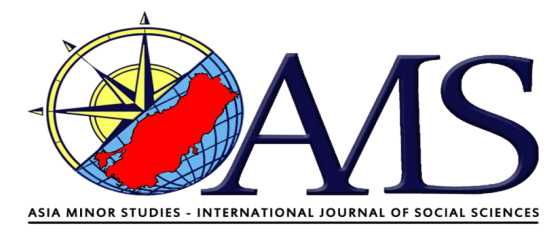

Cilt: 4 Sayı: 7 Ocak 2016 / Volume: 4 Issue: 7 January 2016

\title{
BAĞIMSIZLIK YILLARINDA NAHÇIVAN ÖZERK CUMHURIYYTINDE TOPRAK REFORMU
}

\section{Land Reforms In The Independence Years In The Nakhchivan Autonomous Respublic}

\section{Hazar HÜSEYINOV*}

\section{ÖZ}

Dünyanın bu veya diger bölgesinde olduğu gibi, Nahçıvan'da toprak reformlarının yapılması konusu da bilimsel ilgi yaratıyor. Makalede Nahçıvan bölgesinde toprak reformlarının uygulanması etraflıca analiz edilmişti. Gösterilmiştir ki, bağımsızlık yıllarında Nahçıvan Özerk Cumhuriyeti'nde toprak reformlarının girişimcisi ve kurucusu Azerbaycan halkının ümummilli lideri Haydar Aliyev olmuştur. Onun yorulmaz etkinliği sayesinde Nahçıvan'da kısa zamanda gerçek demokratik ilkeler temelinde toprak reformları başarıyla gerçekleştirilmiştir.

Makalede Nahçıvan Özerk Cumhuriyeti'nde toprak reformları hayata geçirildikten sonra tarımın gelişmesinde olan başarıları arşiv malzemeleri, istatistiki mecmueler, basılı veya diğer yazarların eserlerinden, makalelerden, dönemi basından kullanılarak bilimsel dolaşıma dahil edilmiştir.

Anahtar kelimeler: Nahçıvan, toprak reformu, toprak fonu, özel mülkiyet, tarim.

\section{ABSTRACT}

As at the all regions of the world, the implementation of land reforms in Nakhchivan topic creates a scientific interest. At the article the implementation of land reforms in the Nakhchivan region was analyzed in detail. It is shown that in the years of independence the initiator and founder of the land reforms at Nakhchivan Autonomous Republic was Heydar Aliyev, national leader of Azerbaijan nation. Thanks to his tireless work at Nakhchivan land reforms have been successfully implemented in a short period based on true democratic principles.

\footnotetext{
* Doc.Dr., Nahçıvan Devlet Üniversitesi, Tarih Filoji Fakültesi, Azerbaycan Tarihi Bölümü Nahçıvan /Azerbaycan, xezerhuseynov@gmail.com
} 
Bağımsızlık Yıllarında Nahçıvan Özerk Cumhuriyetinde Toprak Reformu / Hazar HÜSEYINOV

After realization of the land reforms in Nakhchivan Autonomous Republic achievements in the development of agriculture have been included into the scientific turnover on the basis of archive materials, statistic sources, the materials taken from the articles or works published by diffrent authors.

Keywords: Nakhchivan, land reforms, land fund, special property, agrarian area.

\section{GIRIŞ}

Azerbaycan devleti bağımsızlık yıllarında çok böyqük gelişim yolu geçmiştir. Zaman itibariyle çok da büyük olmayan bu dönemde geçilmiş gelişme yolu çeşitli aşamalardan oluşmaktadır. Bu aşamalardan biri de tarımın gelişmesidir. Bilindiği 90'lı yılların başlarında blokaj durumu ile ilgili olarak özerk cumhuriyette ağır ekonomik kriz yaşanmış, tarımsal alanda üretim keskin aşağı düşmüş, bir çok Tarım müesseleri yıkılmış geleneksel pazarlar kayıp, hayvancılık veya tarımın diğer alanlarına ağır zarbeler vurulmuştu.

Böyle gergin dönemde Nahçıvan Özerk Cumhuriyeti'ni derin ekonomik krizden çıkarmak için dahi bir devlet adamı Haydar Aliyev'e ihtiyaç vardı. Milli lider Haydar Aliyev'in Azerbaycan'a, özellikle Nahçıvan'a dönüşü abluka altında yaşayan, Azerbaycan'ın diğer bölgelerinden izole edilen Nahçıvan Özerk Cumhuriyeti yönden gelişmesine güçlü etki göstermişti. Bu bakımdan Azerbaycan Cumhuriyeti'nin bir devlet gibi kurtuluşu ve gelecekteki ekonomik gelişimi Milli lider Haydar Aliyev'in adı ile bağlıdır.

Bilindiği gibi 1980 yılların ortalarından SSCB ekonomisinde başlanan negatif eğilimler Azerbaycan'ın tarımda da uzun süreli durgunluk oluşmasına neden olmuştur. 1991 Aralık ayında Sovyet İmparatorluğu'nun çöküşü sonucunda ülkede üretim alanları dağılmış, toprakların verimliliği korunması, hastalık ve zararlılara karşı mücadele, veterinerlik, seleksiyon ve hayvancılık cins yapısının iyileştirilmesi tedbirlerinin uygulanması durdurulan, gıda sanayi ürünleri üretimi zor duruma düşmüştür.

Azerbaycan bağımsızlığını kazandıktan sonra diğer eski ittifak cumhuriyetlerinde olduğu gibi Azerbaycan'ın ve Nahçıvan'ın da ekonomisinde kriz oluşmaya başlamıştı. O zamanlar tarımda önemli ekonomik biçimleri olan kolhoz ve sovhozlar artık gerekli düzeyde faaliyet gösterebilir bilmiyor ve çiftlikde ekonomik kriz gittikçe derinleşirdi. Bunun yanı sıra, üretim vasteleri, makine ve ekipman fiziksel ve ruhsal yönden giymek, mali gerginliği ile ilgili yenisini almak mümkün olmuyordu.

Bilindiği gibi geçiş dönemi çok zor, ağır ve zıt olur. Bu açıdan geçiş dönemi cumhuriyetimiz için de çok çelişkili olmuş ülkeyi acınacak duruma düşürmüştür. Azerbaycan'ın bağımsızlık kazanması ve piyasa ekonomisine geçitle ilgili olarak geçmiş ittifak cumhuriyetleri ile ilişsiler bozulmuş ve halk ekonominin bütün alanlarında üretimin düşmesi görülmüştür ${ }^{1}$.

${ }^{1}$ Ahmedov N.H. 2005. Nahçıvan ekonomisi gelişme yollarında. Bakü: Bilim, s.66-67. 
Bağımsızlık Yıllarında Nahçıvan Özerk Cumhuriyetinde Toprak Reformu / Hazar HÜSEYINOV

Belirtmek hemen Ermenistan Cumhuriyeti silahlı kuvvetlerinin saldırısı sonucunda Nahçıvan Özerk Cumhuriyeti ablukaya alınmış, ekonomi zor duruma düşmüş, keskin biçimde hammadde eksikliği oluşmuş, mal gönderen ve alıcı müesselərinde ilişkiler tam bozulmuş, sanayi müesselerinin faaliyeti durmuştur.

Aynı zamanda Ermenistan Cumhuriyeti topraklarından geçen elektirik, gaz magistralları, diğer iletişim hatları vahşice tahrip edilmiş, Azerbaycan'ın diğer bölgeleri ile ilişkiler kesilmiş, böylece özerk cumhuriyetin ekonomik ve sosyal hayatında gergin durum ortaya çıktı ${ }^{2}$.

Azerbaycan'ı saran kriz yıkıcı etkisini Nahçıvan'da özellikle büruz veriyordu. Hemen hemen Nahçıvan tamamen Azerbaycan'dan izole şekilde yaşıyordu. Özerk Cumhuriyete gelen demiryolu Ermenistan Devleti tarafindan kesilmiş, Nahçıvan ablukaya koşullarında kuru adaya benziyordu. Başka yerlerle ilişki tamamen kesilmiştir. Ekmek, elektrik, gaz vb. yakıt yoktu. Nüfusun durumu dayanılmaz derecede idi.

"Bilindiği gibi, reformlar yapılmasına dair kanun verilmezden hala çok önce çifliklerde topraklar onunla ilgisi olmayan kişiler arasında dağıtılmış, malsiyah çalıntı, teknik dağıtılmıştır" ${ }^{3}$.

O zamanki Azerbaycan yönetiminin Nahçıvan'a gösterdiği üvey ilişkiler ekonominin tüm alanlarını olumsuz etkisini göstermiş ve kriz durumuna düşürmüştür. Bununla ilgili Milli Lider Haydar Aliyev, Nahçıvan Özerk Cumhuriyeti'nin 75 yıllığına adanmış tören merasimdeki konuşmasında demiştir: "... Nahçıvan'a üvey tutum Azerbaycan'da Sovyet hakimiyeti döneminde, hemen hemen her zaman olmuştur. Hatta bilinmektedir ki, naxçıvanlılar burada çok hay - gürültü salanda Azerbaycan'ın bazı yöneticileri demişlerdi ki, Nahçıvan bizim için bir apensiddir, onu kesip atmak gerekir. Yani çoğu hazırdılar gelip Naxçıvanı işgal etsinler ki, onların canı kurtarsın. Çünkü Nahçıvan onlara çok büyük rahatsızlıklar veriyordu. Böyle üvey ilişkiler çok olmuştur" ${ }^{4}$. Nahçıvan Özerk Cumhuriyeti Ali Meclis Başkanı Haydar Aliyev Naxçıvanı blokaj durumundan çıkarmak, halkı ekmekle sağlamak ve genellikle ablukanın özerk cumhuriyete vurduğu hasarı azaltmak için yollar arıyor ve perispektiv planlar tasarlıyordu.

Nahçıvan'ın Azerbaycan'dan izole şekilde olduğuna göre devlet adamı Haydar Aliyev Nahçıvan'da tarım ve ekonomisinin gelişimine özel dikkat edilmesini birçok konuşmalarında belirtmiştir.

Ülkede pazar ilişkilerine geçişin modern aşamasında tarım-sanayi kompleksinin önünde duran en önemli görev tarımsal üretimini stabilize, halkı gıda, sanayiyi ise hammadde güvenli biçimde temin etmekten ibaretti. Bu sorunların

21997 yılında Nahçıvan Özerk Cumhuriyeti'nin sosyo-ekonomik gelişimi özeti. (1998). Nahçıvan: "Ajami" neşriyatı Poliqrafiya Birliği, s.3.

${ }^{3}$ Ahmedov N.H. 2005. Nahçıvan ekonomisi gelişme yollarında. Bakü: Bilim, s.68.

${ }^{4}$ Aliyev H.A. 2007. Müsteqilliyimiz ebedidir. 22 c Bakü: Azerneşr, s.207-208 
Bağımsızlık Yıllarında Nahçıvan Özerk Cumhuriyetinde Toprak Reformu / Hazar HÜSEYINOV

çözümünde tarım reformları hayata geçirmekle çeşitli tasarruf biçimlerinin gelişmesi, tarım bölümde üretim ve ekonomik potansiyelin kullanımının iyileştirilmesi ve ekonomik etkinliğini yükseltmek önemli bir rol oynuyordu:

Ülkede tarımı kriz durumundan çıkarmak için var olan üretim ve ekonomik potansiyelin verimli kullanmalı, tarımın kendine has özelliklerini dikkate alarak ekonomik mekanizma tekmilleşdirilmeli idi. Gösterilenlerle ilgili tarım birimi piyasa ilişkilerine geçirilmesi esas yön alınarak köklü reformların hayata geçirilmesi, çeşitli ekonomik formlarının düzenlenmesi ve mülkiyet ilişkilerinin geliştirilmesi, esnek fiyat, vergi ve kredi politikaları enjeksiyonu, tarım ve hayvancılığın Dünya deneyiminin başarıları ve bilimsel esaslara geliştirilmesi, idare etmede ekonomik faktörlere öncelik verilmesi için mükemmel programa ve güçlü, yetenekli kişiliğe büyük ihtiyaç duyulurdu. Ülkede oluşan ekonomik ve siyasi krizi büyük dahi, devlet adamı Haydar Aliyev ortadan kaldırabilirdi.

\section{Nahçıvan'da toprak reformlarının hayata geçirildiği tarihi durum}

Nahçivan Ali Meclisi 1991 yılı Eylül 3'te defalarca adaylığını geri almasına rağmen, Haydar Aliyev'i halkın tekidli talebi ile Ali Meclis Başkanı seçti ${ }^{5}$.

Haydar Aliyev, Nahçıvan Özerk Cumhuriyeti'nin Ali Meclisi Başkanı seçildikten sonra Nahçıvan Özerk Cumhuriyeti Azerbaycan'ın sosyo-politik yaşamında önemli rol oynadı. Muhtar ülkede gerçekleştirilen etkinlikler, demokratik değişiklikler, milli dövletçilikle bağlı kabul edilen kararlar Azerbaycan'ın bağımsızlığını pekiştirme yolunda amaçlı faaliyet alanları idi. Nahçıvan'da giden demokratik değişikliklerin sorağı Azerbaycan'dan uzaklara yayıldı. Azerbaycan'ın bağımsız devlet gibi siyasi faaliyetinin konseptial yönleri de işte bu dönemde geliştirilmiştir hazırlanmıştı ${ }^{6}$.

Geçiş dönemini yaşayan ülkemizin önemli sorun, tarımsal alanda ekonomik büyümenin sağlanması toplumda sosyal istikrarın ilkesi olarak görür. Bu süreç daha çok onunla klimalı ki, Tarım genel olarak toplum üyelerinin gıda ve gıda ürünlerine olan ihtiyacını karşılar. Odur ki, bu alanda herhangi bir değişikliğin yapılması gerekli ve zorunlu problemlerden biridir. İşte bu anlamda abluka altında yaşayan Nahçıvan Özerk Cumhuriyeti halk çiftlikinde, özellikle tarım alanlarında değişiklikler yapılıp, reformlar yapmak tarihin talebinden ileri geliyordu.

Tarım alanlarında reformlardan, bu alanda gerçekleştirilen üretimekonomik ilişkilerden söz ederken bütün bunların ilk defa Nahçıvan Özerk Cumhuriyeti'nde hazırlanarak, icrasına işte burada yapıldığını belirtmekte fayda vardir.

Milli Lider Haydar Aliyev 1991-1993 yıllarında Nahçıvan Özerk Cumhuriyeti Ali Meclis Başkanı çalışırken, bu bölgede tarım reformların hayata

\footnotetext{
${ }^{5}$ Azerbaycan tarihi (2008). 7 cilt halinde. VII c. Bakü: Bilim, s.287.

${ }^{6}$ Hacıyev İ.M. 2011. Nahçıvan Özerk Cumhuriyeti'nin sosyo-politik yaşamı, sosyalekonomik ve kültürel gelişimi (1991-2011 yılları). Nahçıvan: "Ajami" Yayıncılık-Poliqrafiya Birliği, s.40-41.
} 
Bağımsızlık Yıllarında Nahçıvan Özerk Cumhuriyetinde Toprak Reformu / Hazar HÜSEYINOV

geçirilmesinin ilk adımları atılmıştır. Aynı dönemde özerk Cumhuriyetin Yüksek Meclisi oturumunda tarım reformu alanındaki özel kararlar kabul edilmiştir. Kararlardan biri - zararla çalışan kolhoz ve sovhozların iptal edilmesi ve kendi veritabanında özel çiftlik kurulması hakkında, ikincisi ise gelirle çalışan kolhoz ve sovhozlarda hayvancıllğı̆ özelleştirilmesi ve bu madde uyarınca özel (kişisel) işletme biçimlerinin oluşturulması amacı taşıyordu ${ }^{7}$.

Belirtmek hemen Sovyet İmparatorluğu dağıldıktan ve Azerbaycan bağımsızlığını kazandıktan sonra önümüzde duran en önemli sorunlardan biri de yeni tarım politikaların uygulanması, reformun yapılması idi. Sovyetler Birliği'nde mevcut iştiraklerin sisteminin dağılması diğer cumhuriyetler gibi Azerbaycan'ı da ağır ekonomik krize soktu. Cumhuriyeti bu krizden çıxarmağın tek doğru yolu ülke çiftliklerini kısa bir sürede yeni ekonomik gerekçelerle restorasyon eütmek idi. $\mathrm{Bu}$ konunun hayata geçirilmesi için öncelikle tarımsal alanda değişiklikler yapıp, reformlar yapmak zarureti yaratıyordu.

Tarım tek sistem olarak formalaşdığından, ekonomik sistemin tipinde ve xarekterində meydana gelen herhangi bir değişiklik, onun yapısı ve alan yapısında da yer buluyor. Daha doğrusu bu karmaşık halk ekonomisinin önemli bir parçası olduğundan, 90'lı yılların başlarında ülke ekonomisinde yaşanan krizler tabii ki, bu alanı da kapsamıştır. Bu yüzden doğal olarak, ülke ekonomisinin sabitleşdirilmesine, ekonomik krizin durdurulmasına yönelik değişiklikler sadece tarım bölmeden başlanmış, gerçekleştirilen reformlar tarımın, onun başlıca üretim aracı sayılan toprağın özelleştirilmesi ile görülmüştür.

"... Tarım alan reformların başlangıç dönemi olarak karakterize edilebilir. Reform mantığ 1 - alanın derin ekonomik ve sosyal krizden çıkarmak, cumhuriyetimizin bağımsızlığını her araç ile yükseltmek, halk ekonomisinin en önemli alanı gibi onun geniş tekrar üretimini girişimcilik ve özel mülkiyyetçilik bazında düzenlenmesi mantık temelinde kurulmuştur. Diğer alanlarla birlikte, tarımsal alanda da reformların yapılması en gerekli vasitelerdendir. Öyle ki, tarihten maddi üretimin başlangıç alanı olan, insan talebinin ödeme doğal-biyolojik deposu olan bu alanın gelişmesinden diğer alanların geliş̧mesi çok bağlıdır" ${ }^{8}$.

İnsanlığın var olduğu döneme bakıldığında görülebilir, tarım tarihsel Azerbaycan'da ekonominin en önemli alanlarından biri olmuş ve nüfusun istihdam sağlanmasında önemli rol oynamıştır. Bu ortamda tarımda ekonomik artışın seviyesinin yükseltilmesi, ülkenin gıda güvenliğinin sağlanması açısından önemli bir rol oynar.

Bilindiği gibi, tarım tarım ülke ekonomisinin oluşumu ve dayanıklı gelişiminde önemli yere ve role sahiptir. Tarihi tecrübeler göstermektedir ki, bu

7 İbrahimova N.H. 2011. Bölgede tarım sektörünün üretim ve ekonomik ilişkilerinin geliştirilmesi yönleri. Nahçıvan: İdea, s.60.

8 İbrahimova N.H. 2011. Bölgede tarım sektörünün üretim ve ekonomik ilişkilerinin geliştirilmesi yönleri. Nahçıvan: İdea, s.16 
Bağımsızlık Yıllarında Nahçıvan Özerk Cumhuriyetinde Toprak Reformu / Hazar HÜSEYINOV

alanda yaşanan herhangi yıkıcı eğilimler sonuçta toplum üyelerinin tarım ve gıda ürünlerine, ekonomik alanın ise xammala gereksinimini karşılamada problem yaratır.

\section{Toprak reformlarının ilk aşaması ve onun hayata geçmesinde Haydar Aliyev'in} rolü

Azerbaycan halkının milli lideri Haydar Aliyev, geçen yüzyılın 90'lı yıllarının başlarında Nahçıvan Özerk Cumhuriyeti'ne rehberlik ederken, oluşan ekonomik kriz ve kaostan ancak reformlar yoluyla çıkagın mümkün olduğunu bildirdi. Tabii o dönemde planlaşdırmaya ve merkezi idari işletme sistemine dayalı sosyalist üretim yöntemi modern dönemle ayaklaşa bilmezdi. Hem de geçmiş ekonomik yönetişim mekanizmasının yıkılması, modern Dünyada sivil pazar ilişkilerinin avantaj teşkil etmesi ve bu süreçlerden kenarda kalmanın mümkün olmadığını gören Haydar Aliyev, ekonomik gelişmesini - girişimcilik ve sahibkarlı̆̆a dayalı yeni ekonomik sistemin olduğunu görüyordu. Onun tefekkürünün ve siyasi iradesinin ürünü olarak, Nahçıvan'da ilk olarak tarımsal alanda radikal bir adım atıldı. Tarım reformları ülkemizde ilk defa olarak ulu önder Haydar Aliyev Nahçıvan Özerk Cumhuriyeti'nde Ali Meclis Başkanı görevinde çalıştı̆ı dönemde başlamıştı.

19926 Nisan Yüksek Kurul toplantısında ekonomik reformlarla ilgili konular tartışıldı, "Nahçıvan Özerk Cumhuriyeti'nde zararla çalışan kolhoz ve sovhozlar hakkında" ve "rentabelli çalışan kolhoz ve sovhozların mal karasının özelleştirilmesi hakkında". Öncelikle Culfa ilçesinin Şurut ve Gal gibi sınır köylerinde deneysel olarak toprak reformuna başland1 ${ }^{9}$.

Ülkede toprak reformunun yapılması kanunauyğun proses olup objektif zorunluluk idi. Bu zorunluluk her şeyden önce ondan kaynaklanıyor, toprak reformu geçirmeden köyde özgür girişimcilik için elverişli koşullar yaratmak, mülkiyetin ve çiftlikin çeşitli biçimlerini geliştirmek gayri mümkündür. Köy de yeni üretim ilişkilerinin oluşumu yolu ile ürün bolluğuna ulaşmak sadece toprak reformu ile ilgilidir.

Toprak reformu Nahçıvan Özerk Cumhuriyeti'nde nüfusun yerleşimi, uzun ömürlü ağaçların, doğal zenginlik olan otlakların ve ormanın korunması amacıyla onlardan kullanımının yasal tabanı ve kullanım kurallarını tanımlar.

Toprak reformunun amacı piyasa yaklaşımını kararlaşdırmak, kişisel girişimcilik üzerinde teşebbüskarlığı ve ilgilerini arttırdı ibarettir. Toprak reformunun temel amacı kolhoz ve sovhoz çiftliklerini iptal etmek, Nahçıvan Özerk Cumhuriyeti'nde kuşatma şartlarında nüfusun gıda ürünlerine telabatını ödemek, nüfusun istihdamını ve yerleşimini sağlamak idi.

9 Hacıyev İ.M. 2011. Nahçıvan Özerk Cumhuriyeti'nin sosyo-politik yaşamı, sosyalekonomik ve kültürel gelişimi (1991-2011 yılları). Nahçıvan: "Ajami" Yayıncılık-Poliqrafiya Birliğii, s.42. 
Bağımsızlık Yıllarında Nahçıvan Özerk Cumhuriyetinde Toprak Reformu / Hazar HÜSEYINOV

Ulu önder Haydar Aliyev tarafindan temeli atılan toprak reformları, onun cumhuriyet Başkanı oldukdan sonra tüm ülkede uygulanmaya başladı. Bu proses Dünyada benzeri olmayan bir şekilde, yani toprakların ücretsiz olarak bedelsiz pay olarak vatandaşlara verilmesi ile hayata geçirildi.

Azerbaycan'da yapılan toprak reformları diğer Bağımsız Devletler Topluluğu (BDT) ülkelerinin daima ilgisini olduğundan, bu alanda oluşturulan yasal dayanağı derinden öğrenmiş, sürecin kontrol edilmesi ve uygulama mekanizmalarına özel dikkat edilmiştir.

Aynı amaçla Ukrayna, Rusya, Beyaz Rusya, Kazakıstan ve diğer devletler Azerbaycan'ın bu alandaki deneyiminden yararlanmak kararına gelmişlerdi ${ }^{10}$.

Azerbaycan Cumhuriyeti'nde 1993 yılı siyasi dönümündən sonra ülkenin siyasi ve ekonomik alanlarını yeni ortamda uyum için küresel ve ciddi reformlar yapılmaya başlandı. Tarım reformların yapısında toprak reformu kendi özel ve müstesna konumu ile seçilir, büyük önemli bir rol oynar. Ülkede gerçekleştirilen toprak reformunun mükemmel karakter taşıması, sonuçta bu radikal değişikliklerin hemen sosyal açıdan tam anlamıyla ağrısız ve kayıpsız geçirilmesine yol açtı. Kısa süre içinde tarımda ekonomik krizi dayandırmakla, ülkede diğer reformların uygulanmasını teşvik verdi.

\section{Toprak reformlarının tüm Azerbaycan üzere uygulanması}

Ulu önder Haydar Aliyev'in yönetimi ile Nahçıvandan başlanan reform programı gerçek ve görünen imkanlara atıfta bulundu. 1996 yıl 16 Temmuz'da ülkenin tarım sektöründe radikal bir adım atıldı. Ülkede 1996 yılında toprak reformu yapıldı. Bu reformu yapmak için yine de dahi devlet adamı Haydar Aliyev'in girişimi ile toprak reformu programı hazırlandı. Programını toprak reformunu sağlayan hukuki tabanı oluşturuldu ${ }^{11}$.

Cumhurbaşkanı Haydar Aliyev'in yönetimi altında hazırlanan, onun siyasi iradesinin ürünü olan "Toprak reformu"nu Yasa kabul etti ${ }^{12}$. Bu kanuna göre, tüm eski Sovyet cumhuriyetlerinden farklı olarak, toprak sosyal adalet ilkesine göre köyde yaşayan vatandaşların özel mülkiyetine verildi ${ }^{13}$. İkincisi toprağın en yararlısı ve deyerlisi özelleşdirilir. Bağımsız Devletler Topluluğu (BDT) mekanının diğer ülkelerinden farklı olarak, vatandaşa yararsız veya az yararlı topraklar değil, geçmiş kolhoz ve sovhozların en iyi ve verimli toprakları verilir. Üçüncüsü, cumhuriyetimizin topraklarında yaşayan tüm vatandaşlara nerede yaşamasından ve kim olursa olsun topraklardan kullanım ve kiralama hakkı verilir, aynı zamanda Azerbaycan'ın her vatandaşı toprak alım satımı sürecinde, toprakla ilgili çeşitli anlaşma bağlanmasında katılabilir. Bu sosyal adalet ilkesi beklenilmekle gerçekleştirilen toprak reformu ülkemizde tarım sektörün dinamik gelişmesine

${ }^{10}$ Rüstemov A.A. vd. 2013. Tarım alanın gelişiminin bölgesel sorunları (Ders malzemesi). Bakü: Avrupa, s.9.

${ }^{11}$ Ahmedov N.H. 2005) Nahçıvan ekonomisi gelişme yollarında. Bakü: Bilim, s.87.

12 "Halk" Gazetesi (1996). 17 Temmuz.

${ }^{13}$ Azerbaycan tarihi (2008). 7 cilt halinde. VII c. Bakü: Bilim, s.387. 
Bağımsızlık Yıllarında Nahçıvan Özerk Cumhuriyetinde Toprak Reformu / Hazar HÜSEYINOV

katkıda bulundu ve az bir sürede reformların olumlu sonuçları kendini göstermektedir.

Ulu önder Haydar Aliyev'in girişimi ile ülkede Azerbaycan vatandaşı olmayan gerçek ve tüzel kişilere toprağa mülkiyyetçilik hakkı verilmemiştir, bu da sadece önemli ekonomik, ayrıca ciddi siyasi önem taşıyor.

Milli Lider Haydar Aliyev'in girişimi ile Ulusal Meclis'in müzakeresine verilmiş "Toprak reformu" Azerbaycan Cumhuriyeti Kanununun 1996 yılının 16 Temmuzunda kabul edilmesi ve 13 Ağustos 1996 yılında bu yasanın uygulanması konusunda Azerbaycan Cumhuriyeti Cumhurbaşkanının kararnamesi ile ülkede toprak reformlarının hayata geçirilmesi süreci başlamış oldu ${ }^{14}$.

"Toprak reformu" Azerbaycan Cumhuriyeti kanununa müafiq olarak, 1995 yılında kabul edilmiş Azerbaycan Cumhuriyeti Anayasasına göre, mülkiyetin aşağıdaki formları tespit edilmiştir:

- Devlet mülkitteti;

- Özel mülkiyet;

- Belediye mülkiyeti;

Şu anda Azerbaycan'da gerçekleştirilen tarımsal reformlar sonucunda toprak üzerinde özel mülkiyet, kamu mülkiyeti ve kolektif mülkiyet teessüs etmiştir.

Özerk cumhuriyetin arazisinin alanı 5,5 bin $\mathrm{km}^{2}$-dir Azerbaycan Cumhuriyeti topraklarının \%6,4'si oluşturmaktadır. Nahçıvan Özerk Cumhuriyeti istatistik idaresinin 01 Ocak 2010 tarihli bilgisine göre günümüzde Özerk Cumhuriyet'in toprak fonu toplam 536300 bin hektardır (Abbasov 2002: 116). Tarıma uygun topraklar 148,4 bin hektardır. Bunun 30 bin ha-1 ekin, 18 bin ha-1 ham ve dince konulmuş topraklar, 79 bin ha-1 biçenek, çimenlik ve otlaklar. Ekim alanının sınırlılığı arazinin dağlık manzara ile ilgilidir. Gerçekleştirilen tarımsal reformlar sonucunda özerk cumhuriyette toplam arazi alanının \%22'si özel mülkiyete, \%33'si belediye mülkiyetine verilmiş, $\% 45$ 'si ise devlete ait bulundurulmuş, 57,8 bin hektarlık arazi özelleşdirilerek sahiplerinin mülkiyeti olmuştur. Genel arazinin 2,5 bin ha-1 (\%0.5'si) ormanlıkdır ${ }^{15}$.

1996 yılı Temmuz 16-da "Toprak reformu" kabul edilmiş kanunun uygulanması için Cumhurbaşkanı Haydar Aliyev Kararname imzaladı. "Devlet toprağ1 üzerinde", "Toprak vergisi hakkında" kanunlar, normatif düzenlemelerin kaydedildi. 1999 yılı 12 Mart "Devlet toprak kadastrı, toprakların izleme ve Yerguruluşu hakkında" ve "Toprak kullanılacağına", aynı yıl Temmuz 18'de "Toprak pazarı hakkında" kanunlar verildi. Tüm bölgelerde toprak kullanıcılar üzere

\footnotetext{
${ }^{14}$ Ahmedov N.H. 2005: Nahçıvan ekonomisi gelişme yollarında. Bakü: Bilim, s.88-90.

${ }^{15}$ Nahçıvan Özerk Cumhuriyeti (Akademik Kuliyev C.B editörlüğünde). (2001). Bakü: Bilim, s.120.
} 
Bağımsızlık Yıllarında Nahçıvan Özerk Cumhuriyetinde Toprak Reformu / Hazar HÜSEYINOV

inventarlaşdırıldı ve ekonomik olarak değerlendirildi. Özel kuruluşların telabatını sağlamak için 1996 yılının Temmuz ayında tarım kredi kassaları yapıldd ${ }^{16}$.

Azerbaycan Cumhuriyeti üzere Dünya Bang'i tarafindan finanse öngörülen 5 örnek özel çiftlik sırasına ulu önder Haydar Aliyev'in talimatı ile Şharur ilçesinindeki Püsyan köyü de dahil edilmişti. Örnek özel tarım işletmeleri yaratmak amacıyla aynı köyde toprak reformu çalışmaları gerçekleştirilmiştir.

1997 yılında bu köyde 1246 aileye 1314,6 hektar arazi özel mülkiyete verilmiș, 1314 aileye devlet eylemi dağıtılmış, bunların tabanında 50 çiftçi çiftlik oluşturulur ${ }^{17}$.

1997 yılında ülke parlamentosu tarafından kabul edilen "Toprak reformu" Kanun, sonuçta toprak reformunun gerçekleştirilmesinin hukuki altyapısını oluşturmuştur. Kısa süre içinde tarımda ekonomik krizin durdurulması ve 1997 yılından itibaren ekonomik büyüme start verilmesi, işte gerçekleştirilen tarımsal reformların başarısını teşkil ediyordu.

Belirtmek hemen 1995 yılından beri gerçekleştirilen tarım reformlarla ilgili, Azerbaycan Cumhuriyeti Dünyada benzeri olmayan reform modeli oluşmaya başladı. Bu reformun esasını tarım sektörünün hukuk, tarımda çoxukladlı çiftlik oluşturmak, özgür rekabetin sağlanması ve özel mülkiyete önem verilmesi teşkil ediyordu.

1999 yıl1 9 Kasımda Başkan özel Fermanla "1999-2000 yılında Azerbaycan Cumhuriyeti'nde tarımsal reformların derinleştirilmesi ve tarımda işletmelerin gelişmesine yardım yapılmasına dair Devlet Programı" nı kabul etti ${ }^{18}$. Bu alanda iş daha da yoğunlaştı. 2000 yılı özerk cumhuriyette toprak reformnda kritik bir yıl olmuş, öngörülen 54,9 bin hektarlık toprağın tamamı özel cifliklere dağıtılmıştı1 ${ }^{19}$.

2001 yılında Nahçıvan'ın 201 köyünde toprak reformu tamamladı. 74 bin 538 ailenin veya 246 bin 902 kişinin özel mülkiyetine 55 bin 92 hektar arazi verilmiştir. "Toprak mülkiyet hakkına dair" Devlet eylemleri hazırlanarak, 70 bin 873 aileye (veya 240 bin 514 kişiye) verilmiştir ki, bu da özel mülkiyetine arazi verilmiş ailelerin 99,2 faizi demektir. Özerk cumhuriyet üzere ortalama her aileye 7 bin 400 metrekare, her kişiye ise 2 bin 239 metrekare arsa alanı düşmüştür ${ }^{20}$.

Toprağın özel mülkiyete verilmesi ile tarımsal alanda varlıkların özelleştirilmesi de tamamlanmıştır. Reform yapılmış çiftliklerde varlıkların toplam değeri 80 milyar 189 milyon manat olmuş, bunun belediye mülkiyetine 64 milyar 973 milyon manat, özel mülkiyete 15 milyar 216 milyon manat değerinde emlak özelleşdirilib verilmiştir.

${ }^{16}$ Azerbaycan tarihi (2008). 7 cilt halinde. VII c. Bakü: Bilim, s.387.

${ }^{17} 1997$ yılında Nahçıvan Özerk Cumhuriyeti'nin sosyo-ekonomik gelişimi özeti. (1998).

Nahçıvan: "Ajami" neşriyatı Poliqrafiya Birliği, s.19-20.

18 "Cumhuriyet" Gazetesi (2001). 24 Subat.

${ }^{19}$ Nahçıvan Özerk Cumhuriyeti (Akademik Kuliyev C.B editörlüğünde). (2001). Bakü: Bilim, s.123.

${ }^{20}$ Ahmedov N.H. 2005: Nahçıvan ekonomisi gelişme yollarında. Bakü: Bilim, s.92. 
Bağımsızlık Yıllarında Nahçıvan Özerk Cumhuriyetinde Toprak Reformu / Hazar HÜSEYINOV

1 Ocak 2002 yıl tarihe Nahçıvan'ın Şharur ilçesi üzere 23 bin 971 aileye, Babek ilçesi üzere 10 bin 860 aileye, Ordubad ilçesi üzere 4 bin 575 aileye, Culfa ilçesi üzere 7 bin 854 aileye, Şahbuz ilçesi üzere 4 bin 118 aileye ve Nahçıvan şehir genelinde 31 aileye-toplam özerk cumhuriyet üzere 51 bin 409 aileye "Toprağın mülkiyet vesigesine dair" şehadetnameler hazırlanmıştır. $\mathrm{Bu}$, öngörülen şehadetnamelerin 71,9 faizini teşkil etmektedir. Şu anda bu çalışma devam etmektedir $^{21}$.

Özerk cumhuriyette 2002 yılı 1 Ekim'e kadar pay alma hakkı olan 71535 bin aileye Devlet eylemleri verilmiş, bunlar 243445 kişiyi kuşatmıştı. Böylece toprak reformlarının ilk aşaması sona ermişti. Reform sonucunda kolhoz ve sovhozların 54856 ha toprak fonu özelleşdirilerek vatandaşlarımızın özel mülkiyetine verilmiştir ${ }^{22}$.

Genel olarak, yapılan toprak reformu sonucunda son yıllarda tarım sektör haylı güçlenmiş ve sadece ülkenin iç kaynaklarını tam ödemek, hatta bazı tarım ürünleri ihracat yeteneği kazanmıştır.

Tahlil ve araştırmalardan anlaşılmaktadır ki, özerk cumhuriyette tarım alanda elde edilen dinamik gelişme milli lider Haydar Aliyev'in uzak görüşlü politikaları sonucunda mümkün olmuştur. Elverişli iklim koşulları, bereketli münbüt toprakların olması, üstelik de alanın gelişmesine kapsamlı devlet kaygısının gösterilmesi kırsal gelişimi, özerk cumhuriyetin toprak potansiyelini verimli kullanıma imkan sağlamıștır. Belirtmek hemen 2012 yılı ürünü için 60 bin 118 hektar alanda ekim yapıldı. Bu da 1996 yılı ürünü için ekili alandan 2,3 katıdır²3.

\section{SONUÇ}

Alınan önlemler sonucunda özerk cumhuriyetde tarımın genel ürününün yapısında ciddi değişiklikler olmuştur. Yapılan reformlar tarım üretimi alanında potansiyelin verimli şekilde reallaşdırılmasına imkan sağlamıştır. Her bir bölgenin spesifik özelliklerine uygun tarım yapısının şekillendirilmesine başlanmıştır. $\mathrm{Bu}$, kendini sonraki yıllarda tarım ürünleri üretimi yapısında da göstermiştir.

Özerk cumhuriyet ekonomisinin tarım alanında pazar ilişkilerinin oluşumu ve gelişmesi tarım üretiminin yeni bölümü ve toprak yapısının oluşmasına, bölmelerarası ilişkilerin tamamen farklı biçim ve içerikte meydana çıkmasına neden olmuştur. Şu anda tarım alanda ekonomik verimlilik ve karşılaştırmalı üstünlükler, esasen, üretim araçları ve metalik ürünler pazarında rekabet ve talep teklifin dengesine göre, fiyatlar mekanizmasının etkisi altında şekillenir. Bu gerçeklik tarım

\footnotetext{
${ }^{21}$ Ahmedov N.H. 2005. Nahçıvan ekonomisi gelişme yollarında. Bakü: Bilim, s.93.

22 Memmedov Q.Ş. 2002. Azerbaycan'da toprak reformları: Yasal ve bilimsel çevre sorunları. Bakü: Bilim,

s.32.

${ }^{23}$ Rüstemov A.A. vd. 2013. Tarım alanın gelişiminin bölgesel sorunları (Ders malzemesi). Bakü: Avrupa, s.10.
} 
Bağımsızlık Yıllarında Nahçıvan Özerk Cumhuriyetinde Toprak Reformu / Hazar HÜSEYINOV

sektörünün üretim sistemini kaynakları sağlayan ve son ürününü tüketicilere ulaştıran altyapı alanların rolünün ve öneminin güçlenmesini korumaktadır.

Tarım reformlarla ilgili köylü aileleri ekonomik kaynaklara, olağanüstü yetkilere, toplumsal ürünün hareketinin her aşamasında tam bağımsızlığa sahip olmakla, ekonomik bağımsızlığa da artık başarılı olabilmişlerdir. Ekonomik bağımsızlığa ise sadece ticari faaliyette mekanizmasının düzenli devlet ayarı esasında elde edilebilir ve bu zaman yüksek ekonomik verim elde etmek mümkündür.

Tarım Nahçıvan Özerk Cumhuriyeti ekonomisinin önde gelen alanlarından biridir. Şu anda özerk cumhuriyetin tarımında üretilen ürünlerin belli bir kısmı diğer ülkelere ihraç edilmektedir. Bu ise özerk cumhuriyetde tarımın hızlı gelişmesinden haber verir.

Esası milli lider Haydar Aliyev tarafından konulan tarım siyaset bugün Azerbaycan Cumhurbaşkanı İlham Aliyev tarafından başarıyla sürdürülüyor. Devlet başkanı ülke ekonomisinin gelişmesinde tarımın önemini vurgulayarak şöyle dedi: "Tarım sektörünün gelişmesine azami özen göstermeliyiz. Bu hem güvenlik, hem ekonomik, hem de sosyal meseledir. Çünkü Azerbaycan nüfusunun yarısı tarım bölgesinde yaşıyor" 24 .

Genel olarak, tarımsal alana devlet kaygısı Sayın İlham Aliyev'in başkanlık döneminde daha da genişletildi. Başkan tarımsal alanda işletmelerin gelişimini teşvik birçok kanunların kabul edilmesi girişiminde etmiş, çok sayıda fermanlar imzalamış ve Devlet programlarını onayladı. Ülkemizin imkanları arttıkça girişimcilere, arazi çiftçilere devletin desteği daha da artırılmıştır. "Tarım ürünleri üreticilerine devlet desteği hakkında", "tohumçuluk ve tingçilik çiftlik satılan I ve II reproduksiyalı tohumlara ve tinglərə göre devlet bütçesinden çiftliklere teşvikin ödeme hakkında", "Azerbaycan Cumhuriyeti'nde buğday üreticilerinin maddi ilgilerinin artırılması ve buğday üretiminin uyarılması ile ilgili ek tedbirler hakkında" imha ve karar verme, "2008-2015 yıllarında Azerbaycan Cumhuriyeti'nde nüfusun gıda ürünleri ile güvenli teminatına dair", "Azerbaycan Cumhuriyeti 2009. 2013 yıllarında sosyal - ekonomik gelişimi" devlet proqramlarının onayı toprak sahiplerinin devletin desteğine güvenini artırmıştır.

Nahçıvan Özerk Cumhuriyeti Ali Meclisi Başkanı tarafından 2008 yılı 17 Eylül tarihli Sərancamı ile onaylanmış "2008-2015 yıllarında Nahçıvan Özerk Cumhuriyeti'nde nüfusun gıda ürünleri ile güvenli teminatına dair Devlet Programı" nın uygulanması yönünde bir sra çalışmalar yapılmıştır. Son yıllarda tarım sektöründe çalışanlara çeşitli amaçlı tercihli kredilerin verilmesi, yeni teknikler ve ekipman alınıp getirilmesi, islah önlemler bu alana olan ilgiyi artırmış, verimlilik yükselmiştir. Gerçekleştirilen tarımsal politikaların etkin bir sonucu olarak 2013

\footnotetext{
24 "Doğu Kapısı" Gazetesi (2013). 30 Ocak.
} 
Bağımsızlık Yıllarında Nahçıvan Özerk Cumhuriyetinde Toprak Reformu / Hazar HÜSEYINOV

yılında Nahçıvan Özerk Cumhuriyeti'nde 337 milyon manatdan çok tarım ürünü üretildi ${ }^{25}$.

Azerbaycan Cumhuriyeti Cumhurbaşkanı Sayın İlham Aliyev demiştir: "Nahçıvan'ın başarılı gelişimi Azerbaycan'ın başarılı gelişmesi demektir. Bizim bağımsızlığımızı güçlendirmek demektir. Burada giden işler beni çok sevindiriyor. Ben eminim ki, bu güzel gelenekler gelecek yıllarda da sürdürülecek ve Nahçıvan Özerk Cumhuriyeti hem ekonomik gelişme hızına göre, hem de altyapı projelerinin seviyesine göre nenki bu bölgede, hatta Dünya çapında öncü yerlerde olacaktır ".

Yapılan çalışmalar sonucunda bağımsızlık yıllarında Nahçıvan Özerk Cumhuriyeti tarımında dinamik gelişmenin sağlanması olunmuş, ayrı ayrı ürünler üzere üretimin seviyesi defalarca artırılmıştır.

\section{KAYNAKLAR}

Azerbaycan tarihi (2008). 7 cilt halinde. VII c. Bakü: Bilim.

Aliyev H.A. 2007. Müsteqilliyimiz ebedidir. 22 c Bakü: Azerneşr.

Abbasov T.A. 2002. Tarımsal kaynak potansiyeli ve ondan verimli kullanımının bölgesel sorunlarl. Bakü: Bilim.

Ahmedov N.H. 2005. Nahçıvan ekonomisi gelişme yollarında. Bakü: Bilim.

"Cumhuriyet" Gazetesi (2001). 24 Şubat.

"Doğu Kapısı" Gazetesi (2013). 30 Ocak.

"Halk" Gazetesi (1996). 17 Temmuz.

Hacıyev İ.M. 2011. Nahçıvan Özerk Cumhuriyeti'nin sosyo-politik yaşamı, sosyalekonomik ve kültürel gelişimi (1991-2011 yılları). Nahçıvan: "Ajami" Yayınc1lık-Poliqrafiya Birliği.

İbrahimova N.H. 2011. Bölgede tarım sektörünün üretim ve ekonomik ilişkilerinin geliştirilmesi yönleri. Nahçıvan: İdea.

1997 yılında Nahçıvan Özerk Cumhuriyeti'nin sosyo-ekonomik gelişimi özeti. (1998). Nahçıvan: "Ajami" neşriyatı Poliqrafiya Birliği.

2013 yılında Nahçıvan Özerk Cumhuriyeti'nin sosyo-ekonomik gelişiminin özeti. (2014). Nahçıvan, "Ajami" neşriyatı Poliqrafiya Birliği, , 96 s.

Memmedov Q.Ş. 2002. Azerbaycan'da toprak reformlart: Yasal ve bilimsel çevre sorunları. Bakü: Bilim.

\footnotetext{
${ }^{25} 2013$ yılında Nahçıvan Özerk Cumhuriyeti'nin sosyo-ekonomik gelişiminin özeti. (2014).
} Nahçıvan, "Ajami" neşriyatı Poliqrafiya Birliği, s.7. 
Bağımsızlık Yıllarında Nahçıvan Özerk Cumhuriyetinde Toprak Reformu / Hazar HÜSEYINOV

Nahçıvan Özerk Cumhuriyeti (Akademik Kuliyev C.B editörlüğünde). (2001). Bakü: Bilim.

Rüstemov A.A. vd. (2013). Tarım alanın gelişiminin bölgesel sorunları (Ders malzemesi). Bakü: Avrupa. 